\title{
PRESSURES INSIDE FREEZING WATER DROPS
}

\author{
By P. J. Visagie \\ (National Physical Research Laboratory, C.S.I.R., Pretoria, South Africa)
}

\begin{abstract}
A small quartz Bourdon tube was employed to measure the pressures that develop inside 7 and $10 \mathrm{~mm}$ diameter water drops freezing in stirred cold liquid baths. In general, the pressure repeatedly rose and then was relieved by cracks in the ice shell as freezing proceeded. The cracking pressure tended to increase with the shell thickness and was dependent on the freezing rate. Pressures up to 76 bar were observed. The effect of the concentration of dissolved gas was investigated. Empirical relationships were found relating cracking pressure to the internal radius of an ice shell and to the average temperature gradient across its thickness.

Résume. Pression dans les gouttes d'eau en congélation. À l'aide d'un petit tube de Bourdon en quartz, on a mesuré les pressions se développant à l'intérieur de gouttes d'eau de 7 et $10 \mathrm{~mm}$ de diamètre, se congélant dans un bain de liquide froid agité. En général, la pression augmentait à plusieurs reprises, se dégageant par des fissures dans l'enveloppe de glace au cours de la congélation. La pression fissurante, qui avait une tendance d'accroître avec l'épaisseur de l'enveloppe, était subordonnée à la vitesse de la congélation. Des pressions allant jusqu'à 76 bar ont été constatées. On a étudié l'effet de la concentration des gaz dissous. Certaines relations ont été observées liant la pression fissurante au rayon interne de l'enveloppe de glace et au gradient moyen de température à travers l'épaisseur de celle-ci.

Zusammenfassung. Innendruck gefrierender Wassertropfen. Wassertropfen von 7 und io mm Durchmesser wurden in einem gut durchmischten Kältebad zum Gefrieren gebracht. Die in ihrem Innern auftretenden Druckwerte wurden mit einem kleinen Bourdonrohr aus Quarz gemessen. Im allgemeinen stieg der Druck zunächst wiederholt an und ging dann mit fortschreitendem Gefrieren beim Springen der Eisschale plötzlich zurück. Der Druck beim Springen stieg mit der Dicke der Eisschale an und hing vom Gefriertempo ab. Druckwerte bis zu 76 Bar wurden beobachtet. Die Wirkung der Konzentration des gelösten Gases wurde untersucht. Empirische Beziehungen des Drucks beim Springen vom Innenradius der Eisschale und zum mittleren Temperaturgradienten im Eis, wurden gefunden.
\end{abstract}

\section{INTRODUCTION}

The expansion of water on freezing leads to high pressures being developed in drops of water that form a complete shell of ice while freezing. The pressure may result in the production of long spikes of ice or other deformation of the shell. The shell may also fracture and eject splinters of ice. Such splinter formation from freezing drops may be important in the electrification of clouds and in the determination of the concentration of ice crystals. Cracking and the consequent rapid release of pressure can give rise to high supersaturation of dissolved air in the water which in turn results in the nucleation of shells of air bubbles at the water-ice interface. Such shells of bubbles have been observed in some hailstones, suggesting that radial-inward freezing of water inclusions occurred at some stage of growth.

It is therefore clear that the processes which occur when a water drop freezes are of considerable importance in cloud physics. Dye and Hobbs (1968) have recently discussed many of the parameters that influence freezing and fragmentation of water drops. This paper treats an aspect hitherto not dealt with, namely the magnitudes of the pressures developed under certain conditions.

\section{Instruments and Technique}

Preliminary observations were made on the freezing of water drops suspended in or falling through cold liquids. The frequency of audible cracking showed that a pressure-measuring device would have to be of rapid response since pressure maxima can occur more frequently than once a second. Furthermore, it would have to measure pressures of at least io bar. This was concluded from observations of the change in volume of air bubbles not enveloped in ice. Another obvious but difficult requirement was that the pressures to be measured should not be influenced by the sensor.

The instrument which was eventually developed was a Bourdon tube made from a quartz capillary and bent into the shape of an inverted $\mathrm{J}$. The form and dimensions are shown in Figure $\mathrm{I}$. The device was calibrated in terms of pressure against deflection of the short limb. 
The sensitivity of the instrument could be increased by reducing the wall thickness at the bend by etching it in hydrofluoric acid. Tubes with various sensitivities were used. The one found to be most suitable gave a deflection of $2 \mu \mathrm{m} / \mathrm{bar}$. Hydrofluoric acid was used to clean the open end of the tube to make the drop wet it (otherwise insertion of the tube into the drop was difficult) and to obtain a strong ice-quartz bond once a shell of ice had formed. The capillary was filled with paraffin in order to prevent water from entering it. Its volume was approximately $30 \mathrm{~mm}^{3}$.

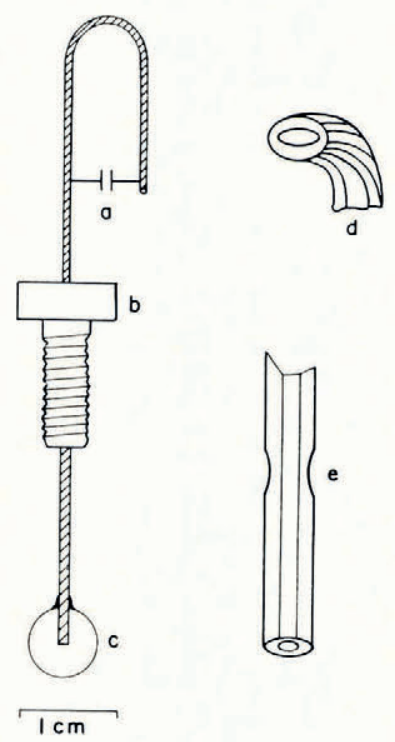

Fig. I. Quartz Bourdon tube.

(a) Movement indicator calibrated in terms of pressure.

(b) Screw for fastening of device to microscope and to calibrating apparatus.

(c) $7 \mathrm{~mm}$ water drop in position for measurements.

(d) Detail showing flattened cross-section of bend.

(e) Constriction at $3.5 \mathrm{~mm}$ from open tip of instrument.

The technique of using the Bourdon tube to measure the pressure inside a freezing drop several millimetres in diameter was as follows: A weak density gradient was set up in a mixture of paraffin and tetrachloroethylene at $-10^{\circ} \mathrm{C}$. The drop was suspended in this and the bath height adjusted so that the combined weight, buoyancy and surface tension forces kept the tip of the Bourdon tube at the centre of the drop. Silver iodide was used to nucleate the drop. Its average temperature at the moment when freezing commenced was rarely below $-6^{\circ} \mathrm{C}$ (by calculation) but the surface layer must have been near $-10^{\circ} \mathrm{C}$. In general, the pressure repeatedly rose and fell as freezing proceeded. Deflections of the tube were observed through a stereo-microscope and their magnitudes were recorded vocally on magnetic tape. The times of occurrence of the measured pressures were afterwards determined from the recording using a stop-watch.

The attached Bourdon tube acts as a temporary safety-valve while pressure is developing inside a drop. The rate of pressure increase for a drop with a tube must therefore be less than the rate for a drop without a tube. The effect of the measuring device depends on its sensitivity. The more sensitive it is, the more its volume changes with a given change in pressure. The tube used for most of the experiments was found to require the freezing of $0.1 \mathrm{~mm}^{3}$ of water to indicate one bar of pressure increase inside a drop. The highest pressures recorded were more than $5^{\circ}$ bar and they occurred towards the end of freezing. They must often have been limited by the presence of the instrument since $5^{\circ}$ bar would have required the freezing 
of $5 \mathrm{~mm}^{3}$ of water. Another reason for not having recorded the highest pressures is that the tip of the Bourdon tube was not always located at the centre of the drop.

\section{Results}

\section{(a) Experiments in an unstirred bath}

Experiments were mostly made on drops of about $7 \mathrm{~mm}$ diameter ( $0.2 \mathrm{ml}$ in volume). Initially a drop, saturated with air at $15^{\circ} \mathrm{C}$, was frozen and observed at $-10^{\circ} \mathrm{C}$ in the unstirred bath in which it was affixed to the Bourdon tube. Such a drop tended to freeze asymmetrically due to the natural convection around the drop (Hallett, i 965). A large knob tended to develop on the underside of the drop. In other cases openings in the shell at junctions of differently oriented surface dendrites persisted until very close to the completion of freezing. The life of such an opening was prolonged by interior water at $0^{\circ} \mathrm{C}$ being continually expelled through it and warming its vicinity as the shell grew inwards. The water that was forced out at these weak points in the shell formed knobs by spreading and freezing on the surface. Sometimes spikes were formed when the water did not spread out. No pressure increases were found while such protuberances were growing and liquid water was visible. However, as soon as they stopped growing, i.e. the opening sealed, the pressure built up to about 20 bar after which fracture occurred and the pressure dropped.

In order to get symmetrical freezing, thin shells were allowed to form in the unstirred bath at $-10^{\circ} \mathrm{C}$ after which the drops were transferred to a stirred bath at the desired temperature for the rest of the experiments.

\section{(b) Effect of cooling-bath temperature on pressures}

Water drops saturated with air at ${ }_{1} 5^{\circ} \mathrm{C}$ were frozen, with Bourdon tubes attached, in a stirred bath at temperatures from -2 to $-20^{\circ} \mathrm{C}$ after shells had been formed at $-10^{\circ} \mathrm{C}$. Pressures as high as 76 bar were found. The following trends were noted:

i. The pressure at which the shell fractured increased as the shell became thicker;

ii. More rapid freezing gave rise to greater fracture pressures.

These trends are illustrated in Figure 2. Exceptions to them can also be seen. For example, cracking occurred a number of times at the same pressure in Figure 2(c) during the time interval marked $\mathrm{A}$. In this period water was extruded through a crack or cracks and it spread and froze on the surface of the drop, forming a knob. The same observation was made during interval c, Figure 2(b). Figure 2(b) also shows a period, marked B, when no over-pressure developed. A thin spike, $6 \mathrm{~mm}$ long and $\mathrm{I} \mathrm{mm}$ diameter, formed in this time. Eventually the spike sealed off and the pressure again built up.

The drops of Figures 2(a) and (d) remained essentially spherical. The one frozen at $-4.7^{\circ} \mathrm{C}$ developed a slight bump and about eight small knobs or short spikes, $0.5 \mathrm{~mm}$ high with bases $\mathrm{I} \mathrm{mm}$ in diameter. The overall deformation of the drop frozen at $-12.8^{\circ} \mathrm{C}$, Figure 2(a), was slight, and only one thin spike, I $\mathrm{mm}$ high, formed. The drop which froze more rapidly developed much higher pressures than the warmer one.

The freezing drops were deformed in every case but the extent of the distortion was found to vary from drop to drop. Instances when the fracture pressure remained constant with time during freezing or when no over-pressure developed were associated with the development of a protuberance.

After completion of freezing, the cracks in the shells were observed visually, sometimes with the aid of the stereo-microscope. At bath temperatures below $-5{ }^{\circ} \mathrm{C}$ they were mostly situated in between thin layers of clear and milky ice extending more or less radially into the drop. The cracks were therefore approximately flat planes and extended up to the surface. The layers of clear ice were the initial dendrites that formed at the commencement of freezing, while the milky layers were formed in between these by nucleation of air bubbles as the shell closed. Cracks were also observed at the bases of spikes and knobs. In the drop frozen in the 
$-4.7^{\circ} \mathrm{C}$ bath, however, only one crack was found to extend to the surface. The other cracks (about 7) were much shorter in length, sharply curved and did not reach the surface of the shell. These curved cracks were not obviously related to the small knobs that formed on the surface of the drop.

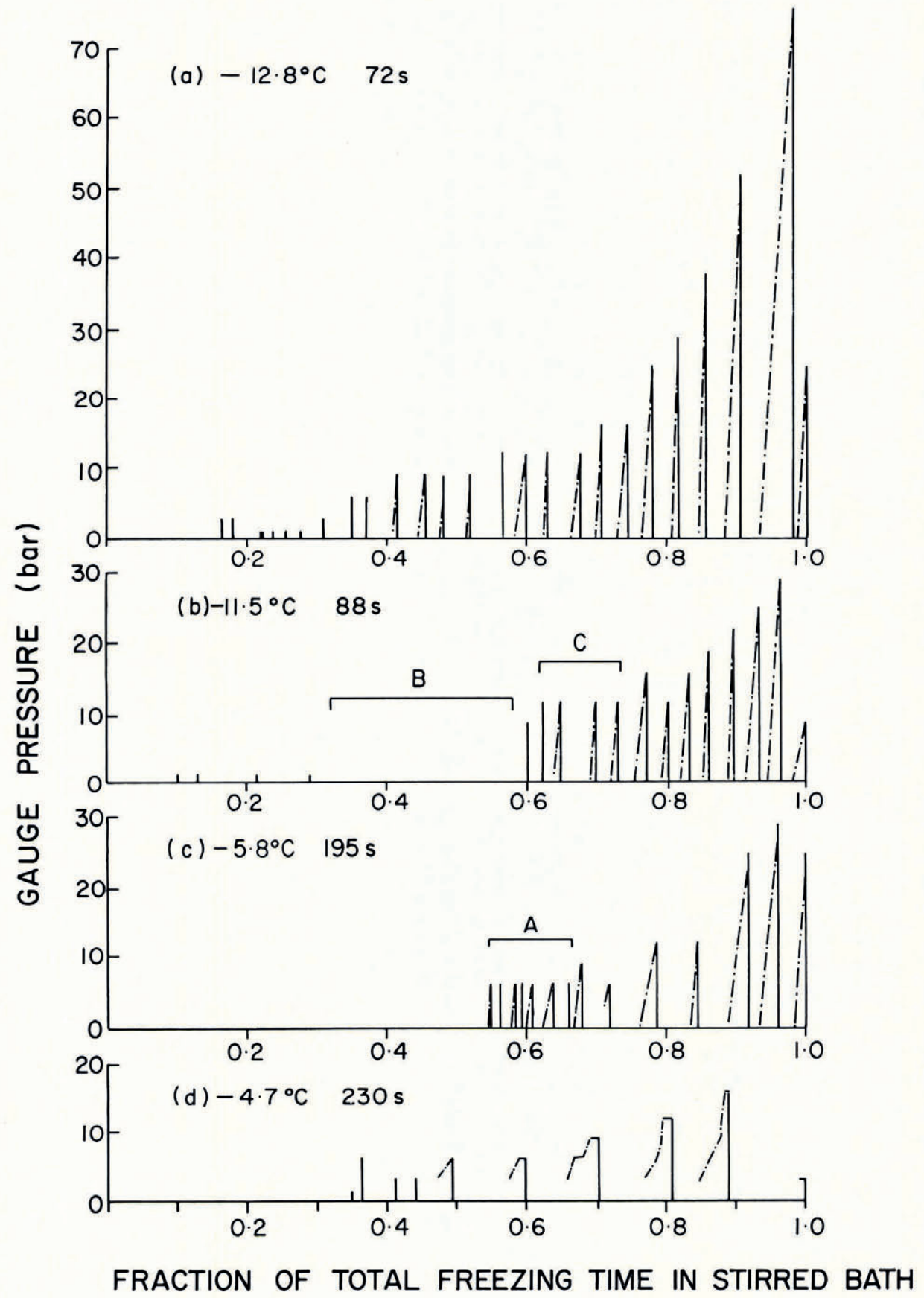

Fig. 2. Pressure-time histories of four $7 \mathrm{~mm}$ diameter water drops frozen in a stirred cooling bath. Bath temperatures and total freezing times are as shown. Broken lines indicate rising pressures and peaks are where cracking occurred. 
Pressure plateaux with durations of more than one second, as shown by Figure $2(\mathrm{~d})$, were found to occur immediately before fracturing when bath temperatures were above about $-5^{\circ} \mathrm{C}$. Plateaux were not detected at lower bath temperatures. If they existed, their durations must have been very short. Pressure plateaux may be due to the cushioning effect of air bubbles or to plastic deformation of the ice.

In $7 \mathrm{~mm}$ water drops at a cooling bath temperature of $-3.4^{\circ} \mathrm{C}$ a maximum pressure increase of only 2 bar was recorded, while at higher temperatures no pressure increases were detected and no audible cracks were heard.

\section{(c) The effect of gas content}

Water with reduced gas content was obtained by melting ice which had no visible air bubbles in it. Drops of this water, when frozen in a stirred bath at $-10^{\circ} \mathrm{C}$, formed thicker shells of clear ice before bubble formation commenced than drops saturated with air at $15{ }^{\circ} \mathrm{C}$. Fracturing of the shell was more frequent in these drops than in drops with more air. They cracked on the average 22 times per drop as compared with 18 times for the drops saturated at $15{ }^{\circ} \mathrm{C}$. However, there was considerable variation in behaviour from drop to drop, dependent on the deformation suffered by the shells, so that this small difference between the numbers of cracks is probably not significant. The measured cracking pressures were not significantly different either. Some of the variations can be attributed to escape of air. Sometimes streams of bubbles were seen to emerge from cracks in the shell. This loss, when it occurs, obviously changes the conditions inside the shell.

This escape of gas bubbles was far more pronounced when the water was saturated with carbon dioxide at $\mathrm{I}^{\circ} \mathrm{C}$. These drops produced relatively huge, mis-shapen protuberances from which copious amounts of gas could be seen to issue. Usually no overpressure was detected but there were exceptions. The pressure-time diagram of one drop containing carbon dioxide is shown in Figure 3. The shell cracked only twice, the first fracture occurring after a long period of slowly increasing pressure, when a large knob formed, followed by a rapid pressure build-up. Yielding of the shell to form a knob was probably enhanced by the very large number of gas bubbles entrapped in the ice. The slow rate of pressure build-up was similar to that found in air-saturated drops at temperatures slightly below $-3{ }^{\circ} \mathrm{C}$, as illustrated in Figure $2(\mathrm{~d})$ by the $-4.7^{\circ} \mathrm{C}$ case. That drop had much less dissolved gas than the one containing carbon dioxide and the extrusions were comparatively small in spite of the higher temperature of the shell. It is conjectured that the high rate of pressure increase in the

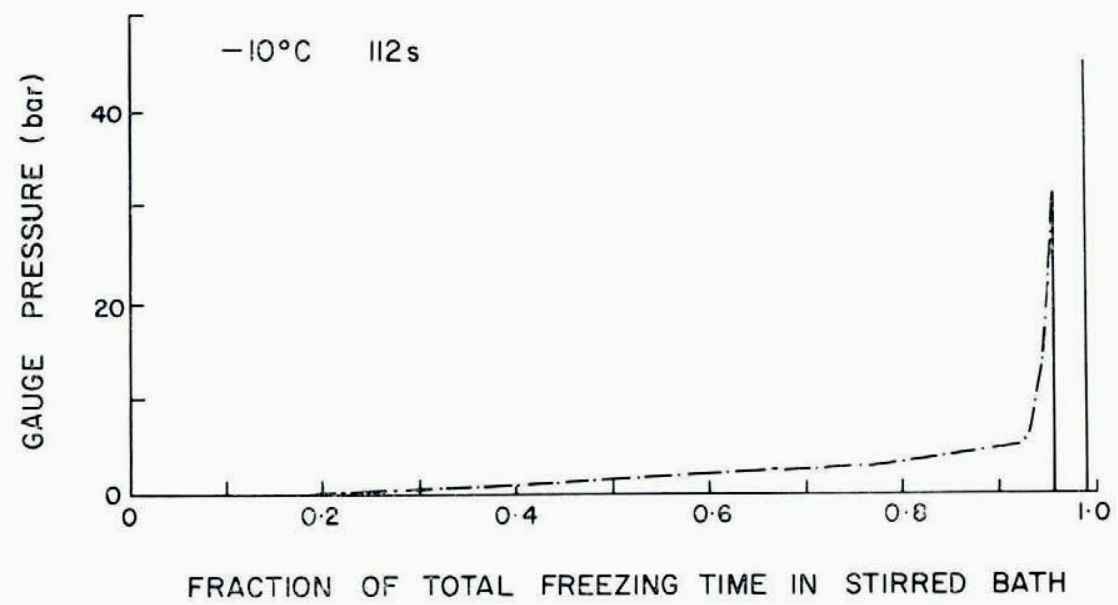

Fig. 3. Pressure-time history of a $7 \mathrm{~mm}$ diameter drop of water saturated with carbon dioxide at $1^{\circ} \mathrm{C}$ and frozen in a stirred liquid bath at $-10^{\circ} \mathrm{C}$. The drop was completely frozen after $112 \mathrm{~s}$ in this bath. The two peaks are where cracking occurred. (The pressure rise before the second peak occurred too rapidly for values of pressures to be recorded.) 
carbon-dioxide-saturated drop started after the base of the knob had been sealed by inward freezing. This rate of $8 \mathrm{bar} / \mathrm{s}$ is typical of that observed in the drops saturated with air and frozen in a stirred bath at $-10^{\circ} \mathrm{C}$. The increasing pressure up to the second fracture was not observed, but the pressure reached before cracking is within the range found for drops without carbon dioxide at this temperature.

\section{(d) The effect of drop diameter}

The technique and instrument used did not permit the investigation of drops much smaller than $7 \mathrm{~mm}$ diameter. Larger ones were, however, tested. They froze more slowly and tended to form pressure-accommodating protrusions even more readily than the $7 \mathrm{~mm}$ drops. Consequently their pressure-time histories were more irregular although the general trend of increasing fracture pressure with time was observable. However, it has been found that, compared with smaller drops, the cracking pressure of bigger drops increased less rapidly as freezing proceeded, see Section 4 and Figures 4 and 5 .

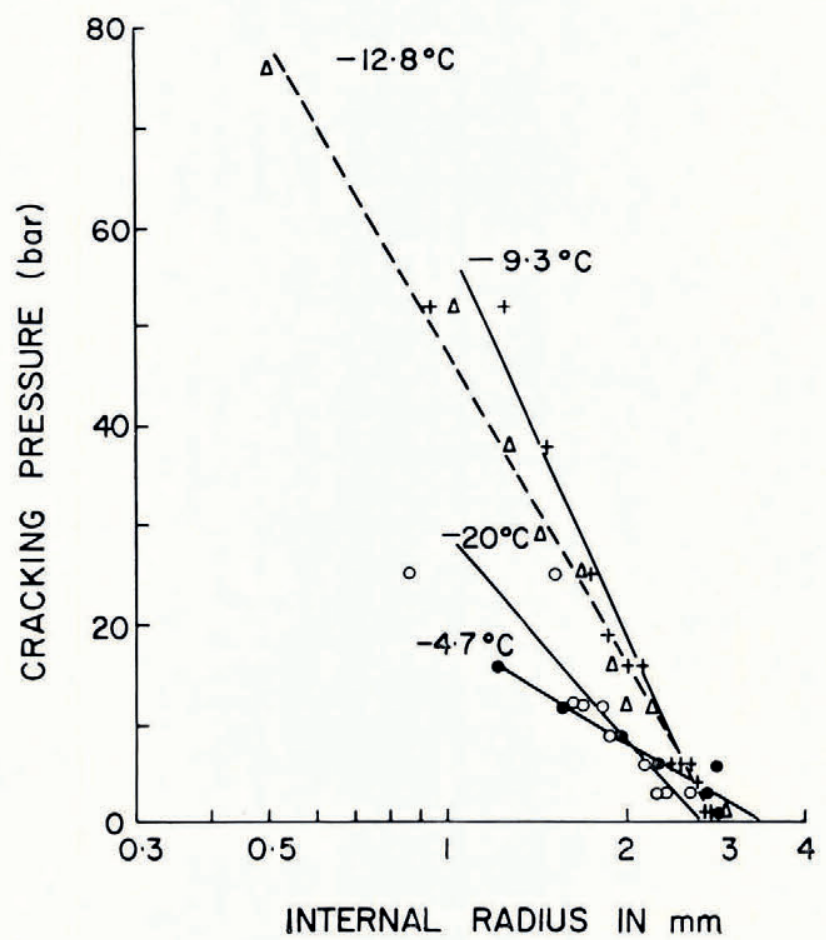

Fig. 4. Cracking pressure versus calculated internal radius of ice shell of four $7 \mathrm{~mm}$ drops frozen in stirred cooling baths at temperatures as indicated.

\section{Empirical Relationship}

Although Figure 2 shows the behaviour of air-saturated drops to be highly irregular, an attempt was made to relate cracking pressure to shell thickness and cooling-bath temperature. The internal radii of the ice shells at the moments of cracking have been calculated, using the expression for the steady-state heat conduction through a spherical shell that Mason (I956) employed in his study of the melting of hailstones. No account was taken of air content, bubble distribution, the influence of cracks or the existence of non-radial dendrites that might have formed in the interior of the drop at the moment of freezing due to supercooling. It was found 


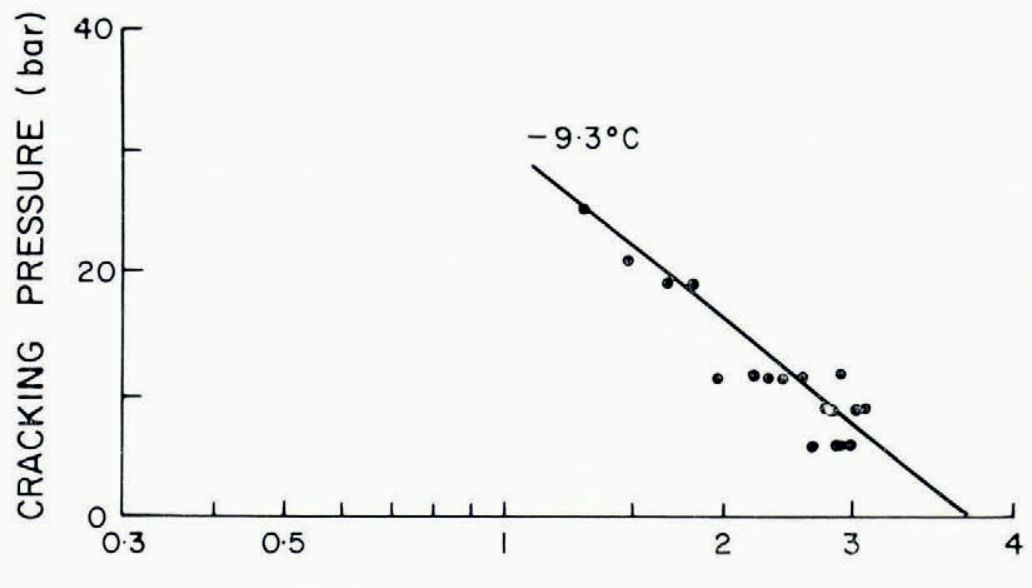

INTERNAL RADIUS IN $\mathrm{mm}$

Fig. 5. Cracking pressure versus calculated internal radius of ice shell of a $10 \mathrm{~mm}$ drop frozen in a stirred cooling bath at $-9 \cdot 3{ }^{\circ} \mathrm{C}$.

for the drops air-saturated at ${ }_{1} 5^{\circ} \mathrm{C}$ that the cracking pressure is a linear function of the logarithm of the internal radius, $r$, as shown by Figure 4. The rate of decrease of $r, \mathrm{~d} r / \mathrm{d} t$, was governed by the stirring rate. In these experiments the stirring rate was such that $\mathrm{I} / r \propto \mathrm{d} r / \mathrm{d} t$. The scatter in the measured values of pressures and the uncertainty in the observed times makes it impossible to decide whether the relation $p$ versus $\ln r$, or $p$ versus $\ln (\mathrm{d} r / \mathrm{d} t)$, gives the best fit to a straight line, where $p$ is the cracking pressure. However, only $p$ versus $\ln r$ will be discussed in this paper. The fracture pressure of a drop containing air was therefore

$$
p=-\alpha \ln \left(r / r_{\mathrm{o}}\right)
$$

where $\alpha$ is the slope of the straight line and $r_{0}$ is the radius-axis intercept, i.e. the internal radius when the shell first sealed.

The radius $r_{0}$ varied from drop to drop with the one frozen in the $-20^{\circ} \mathrm{C}$ bath closing up last. This is most probably due to thermal stresses cracking the shell when the drop was suddenly introduced into the appreciably colder stirred bath. One shell was observed to shatter into a few pieces immediately after immersion into a stirred bath at $-25^{\circ} \mathrm{C}$. These thermal stresses do not seem to have such obvious effects when the temperature difference between baths is smaller.

The slopes, $\alpha$, of the straight lines are clearly dependent on the cooling-bath temperatures of the experiments. At a cooling-bath temperature $-3 \mathrm{C}$, where no pressure increase was detected, the slope can be taken as zero. Down to about $-10^{\circ} \mathrm{C} \alpha$ increases rapidly and approximately linearly after which it decreases at a slower rate. In any particular drop, $\alpha$ is very sensitive to the times of occurrence of the last few cracks relative to the completion of freezing. Below $-10^{\circ} \mathrm{C}$ accuracy in timing became increasingly difficult to achieve due to the rapidity of freezing. The decrease in slope at cooling-bath temperatures below $-\mathrm{IO}^{\circ} \mathrm{C}$ may therefore be apparent and due only to short-comings in technique. However, the mode of freezing must have been more complex than the smooth spherical shell model assumed, since dendrites which formed almost immediately after nucleation extended throughout the interior of the drop. These might become more pronounced at higher freezing rates, providing deeper indentations in the colder shells at which cracks would preferentially start.

In a given stirred bath the slope $\alpha$ of $p$ versus $\ln r$, is a function of the size of the drop. This is shown in Figure 5 where the results are given for a $10 \mathrm{~mm}$ diameter $(0.4 \mathrm{ml})$ drop frozen in a bath at $-9 \cdot 3^{\circ} \mathrm{C}$. The scatter of the points is largely due to a great deal of deformation suffered by the drop. The slope of the least-squares line for it is 29 compared to 6o (when pressures were measured in bars) for the $7 \mathrm{~mm}$ drop at the same bath temperature. In these 
experiments the average temperature gradient across the ice shells remained fairly constant throughout the freezing process in the stirred bath and is adequately given by:

$$
G=-t / b
$$

where $G$ is the average temperature gradient, $t$ is the cooling-bath temperature $\left({ }^{\circ} \mathrm{C}\right)$, and $b$ is the outside radius of shell. By plotting $\alpha$ versus $G$, Figure 6 , the slopes of the $7 \mathrm{~mm}$ drops and of the $10 \mathrm{~mm}$ one fall on a single band which also represents several other $7 \mathrm{~mm}$ drops not shown in Figure 4. It is therefore concluded that the cracking pressure of a freezing drop is a function of the average temperature gradient across the shell.

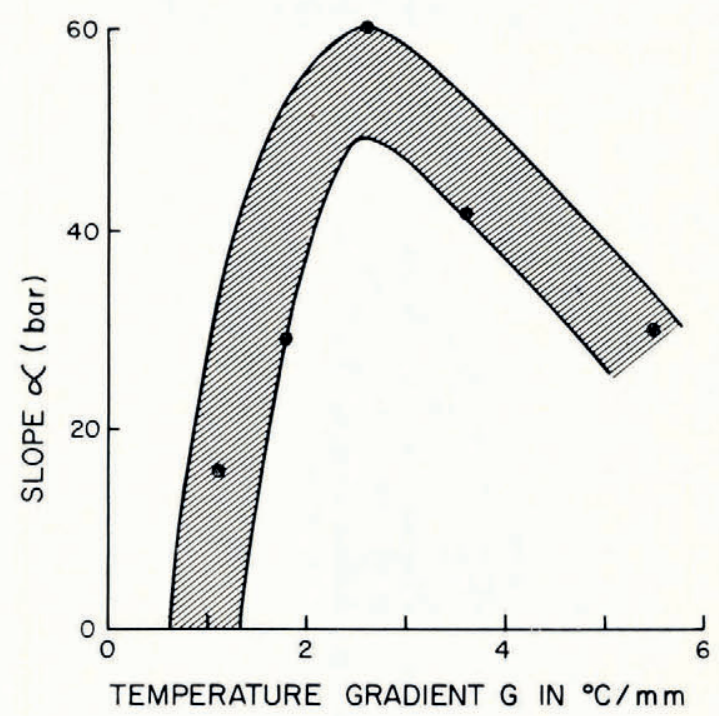

Fig. 6. Graph of $\alpha$ versus $G$ where the points were obtained from the slopes, $\alpha$, of the lines in Figures 4 and 5 and $G$ the average temperature gradients. Other cases not shown in Figures 4 and 5 fell within the shaded band.

\section{Discussion}

An important result of this investigation is the finding that freezing water drops may repeatedly sustain pressures of tens of bars. The highest pressure recorded was 76 bar after the shell had cracked 24 times. It was clear that the thickness of the shell was not the governing parameter because high pressures were recorded in some of the drops although they had cracks which remained at least $0.5 \mathrm{~mm}$ wide at the surface. Of course, the deeper parts of the cracks must have been sealed.

The influence of the measuring apparatus during the last stages of freezing makes it uncertain that the logarithmic relationship of pressure versus internal radius will hold right up to the end of freezing. The curve in Figure 4 with the steepest slope, when extrapolated, gives reasonable values of a few hundred bars at internal radii of a few micrometres. However, the presence of air bubbles when the freezing is almost complete would probably prevent the actual development of such high pressures.

Figure 6 can be used to estimate the pressures which are needed to fracture shells of various thicknesses when the ice is growing at various rates. This would be done by drawing straight lines, as in Figures 4 and 5, with slopes obtained from Figure 6 and with appropriate values for the intercepts on the abscissa (i.e. $r_{0}$, the internal radii at which pressure increases first develop). Such results would apply to drops of water saturated with air at $15^{\circ} \mathrm{C}$ and cooled in a liquid bath. Drops in the atmosphere at sub-zero temperatures will contain more 
dissolved air and may therefore behave differently as indicated in Section 3 (c). Also, it would be unwise to apply these results to drops much smaller than those on which the observations were made. In any event, the temperature gradient across the shell of a cloud droplet freezing in the atmosphere will, even shortly after freezing has commenced, at temperatures just below zero be outside the range of Figure 6 . There are therefore still numerous problems to be investigated before the fracture behaviour of freezing hydrometeors can be predicted. The exact conditions of freezing must be known and taken into account before results of this work could be applied to cloud conditions.

\section{Acknowledgement}

I thank Dr A. E. Carte for his invaluable help and advice in all stages of this work.

MS. received 12 September 1968

\section{REFERENCES}

Dye, J. E., and Hobbs, P. V. 1968. The influence of environmental parameters on the freezing and fragmentation of suspended water drops. Fournal of the Atmospheric Sciences, Vol. 25, No. 1, p. 82-96.

Hallett, J. 1965. On the structure of precipitation elements formed by the freezing of supercooled water. International Conference on Cloud Physics, Tokyo and Sapporo, May 24-7une I, 1965. Proceedings. Sponsored by International Association of Meteorology and Atmospheric Physics of the International Union of Geodesy and Geophysics; World Meteorological Organization; Science Council of Japan [and the] Meteorological Society of Japan. Tokyo, p. 201-04.

Mason, B. J. 1956. On the melting of hailstones. Quarterly Fournal of the Royal Meleorological Society, Vol. 82, No. $35^{2}$, p. 209-16. 